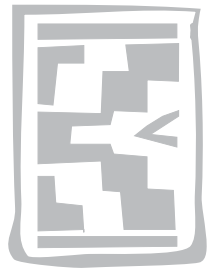

\title{
Epidemiological studies of parasitic gastrointestinal nematodes, cestodes and coccidia infections in cattle in the highveld and lowveld communal grazing areas of Zimbabwe
}

\author{
D.M. PFUKENYI ${ }^{1}$, S. MUKARATIRWA ${ }^{2}$, A.L. WILLINGHAM ${ }^{3}$ and J. MONRAD ${ }^{3}$
}

\begin{abstract}
PFUKENYI, D.M., MUKARATIRWA, S., WILLINGHAM, A.L. \& MONRAD, J. 2007. Epidemiological studies of parasitic gastrointestinal nematodes, cestodes and coccidia infections in cattle in the highveld and lowveld communal grazing areas of Zimbabwe. Onderstepoort Journal of Veterinary Research, 74:129-142

Between January 1999 and December 2000 faecal samples from 16264 cattle at 12 dipping sites in the highveld and nine in the lowveld communal grazing areas of Zimbabwe were examined for gastrointestinal (GI) nematode and cestodes eggs, and coccidia oocysts. Strongyle larvae were identified following culture of pooled faecal samples collected at monthly intervals. The effects of region, age, sex and season on the prevalence of GI nematodes, cestodes and coccidia were determined. Faecal egg and oocyst counts showed an overall prevalence of GI nematodes of $43 \%$, coccidia $19.8 \%$ and cestodes $4.8 \%$. A significantly higher prevalence of infection with GI nematodes, cestodes and coccidia was recorded in calves $(P<0.01)$ than in adults. Pregnant and lactating cows had significantly higher prevalences than bulls, oxen and non-lactating (dry cows) $(P<0.01)$. The general trend of eggs per gram (epg) of faeces and oocysts per gram (opg) of faeces was associated with the rainfall pattern in the two regions, with high epg and opg being recorded during the wet months. The most prevalent genera of GI nematodes were Cooperia, Haemonchus and Trichostrongylus in that order. Strongyloides papillosus was found exclusively in calves. Haemonchus was significantly more prevalent during the wet season than the dry season $(P<0.01)$. In contrast, Trichostrongylus was present in significantly $(P<0.01)$ higher numbers during the dry months than the wet months, while Cooperia and Oesophagostomum revealed no significant differences between the wet and dry season. These findings are discussed with reference to their relevance for strategic control of GI parasites in cattle in communal grazing areas of Zimbabwe.
\end{abstract}

Keywords: Age distribution, cattle, cestodes, coccidia, communal grazing, epidemiology, gastrointestinal nematodes, seasonal occurence, Zimbabwe

\section{INTRODUCTION}

In rural Zimbabwe, cattle are grazed on communal pastures throughout the year. The animals do not

1 Clinical Veterinary Studies, Faculty of Veterinary Science, University of Zimbabwe, P.O. Box MP167, Mt Pleasant, Harare, Zimbabwe. Email: dmpfukenyi @vet.uz.ac.zw

2 Paraclinical Veterinary Studies, Faculty of Veterinary Science, University of Zimbabwe, P.O. Box MP167, Mt Pleasant, Harare, Zimbabwe

3 Danish Centre for Experimental Parasitology, Dyrlaegevej 100, DK-1870, Frederiksberg C, Copenhagen, Denmark

Accepted for publication 7 March 2007-Editor receive any supplement (Pandey, Chitate \& Nyanzunda 1993) and fodder shortage is usually a problem, even in the rainy season (Moyo, Bwangomoi, Hendrikx \& Eysker 1996). Anthelmintic treatment of communal cattle is either non-existent or very occasional and irregular (Pandey et al. 1993). A combination of poor nutrition, communal grazing, high stocking rate and lack of anthelmintic medication may result in heavy worm burden in communally grazed cattle (Pandey et al. 1993).

There have been studies on internal parasites of cattle in the communal farming areas of Zimbabwe (Pandey 1989; Obwolo, Hill, Nyathi, Ogaa, Odiawo, 
Llewelyn, Vickers \& Moyo 1992; Pandey et al. 1993; Vassilev 1994, 1999; Moyo et al. 1996). These studies have shown that the predominant parasites in cattle were Fasciola gigantica, amphistomes, and strongylid nematodes, with coccidia, Schistosoma mattheei, Moniezia spp. and Trichuris spp. being less prevalent. However, all the earlier studies carried out in Zimbabwe concentrated on one agroclimatic region of the country, that is the highveld with the lowveld being completely neglected. The diverse agroclimatic conditions, animal husbandry practices and pasture management have been shown to largely determine the incidence and severity of various parasitic diseases in a region (Jithendran \& Bhat 1999). Therefore, information on the epidemiological patterns of the parasitic diseases in different agroclimatic zones of the country would provide a basis for evolving strategic and tactical control of these parasitic diseases (Jithendran \& Bhat 1999).

This study was carried out to determine the level of gastrointestinal nematodes, cestodes and coccidia infections of cattle in the highveld and lowveld communal farming areas of Zimbabwe, and to determine the effect of agroclimatic zones, age and season on the prevalence of gastrointestinal parasitism in order to form a basis for formulating strategies for parasite control.

\section{MATERIALS AND METHODS}

\section{Study location}

Based mainly on rainfall and temperature, Zimbabwe is divided into agro-ecological regions I, II, III, IV and $\mathrm{V}$ (Fig. 1). On the basis of altitude, the country is also divided into three major relief regions, the Highveld (1200-2000 m), Middleveld (900-1200 m) and the Lowveld (below $900 \mathrm{~m}$ ).

The rainy season is from November/December to March/April and the dry season occurs from April/ May to October/November. The respective mean annual rainfall for regions I-III is $1000 \mathrm{~mm}, 750$ $1000 \mathrm{~mm}$ and $650-800 \mathrm{~mm}$. Region IV receives low rainfall of $450-650 \mathrm{~mm}$ and is subject to periodic droughts. In region $\mathrm{V}$, rainfall is very erratic and is less than $500 \mathrm{~mm}$ per annum.

Hills and valleys characterize the topography of the highveld in which streams and rivers are located. Dams, rivers and marshy areas which serve as common watering places for livestock are common in the area. In the lowveld, the topography is generally flat land, with man-made dams serving as watering points for livestock. Pastures in the communal grazing areas are composed of uncultivated grassland and scrub bush.

Seven districts were randomly selected within agroecological regions II and III (Highveld) and IV (Lowveld) (Fig. 1) - four from the Highveld and three from the Lowveld (Table 1).

\section{Selection of study sites}

Dip tanks were chosen as the study sites owing to the availability of handling animal facilities and access to larger populations of cattle. Three dip tanks were randomly selected from each district, giving a total of 21 study sites-12 from the Highveld and nine from the Lowveld (Table 1). In these areas cattle were dipped weekly during the rainy season and fortnightly during the dry season for the control of ticks.

\section{Animals}

Local indigenous cattle used in the study were Sanga type (a stabilized Bos taurus x Bos indicus cross), commonly known as "Mashona". Cattle from each of the study sites were categorized into calves (less than 12 months old), weaners (1-2 years old) and adults (over 2 years old). Calves and weaners were further divided into males and females, and adults into dry, lactating and pregnant cows, oxen and bulls. Rectal faecal samples were collected from each category of cattle once every month. The survey covered the period from January 1999 to December 2000.

\section{Parasitological analysis}

Faecal samples were quantitatively examined for nematode, cestode eggs and coccidia oocysts by the modified McMaster technique (Ministry of Agriculture, Fisheries \& Food 1986) on $4 \mathrm{~g}$ of faeces using saturated sodium chloride solution and each egg counted represented 50 eggs. The results were expressed as eggs per gram of faeces (epg) or oocysts per gram of faeces (opg).

Monthly, pooled faecal samples from each category of cattle for each dip tank were cultured for larval identification (Ministry of Agriculture, Fisheries \& Food 1986). One hundred third-stage strongyle larvae $\left(\mathrm{L}_{3}\right)$ including Strongyloides papillosus larvae from each culture were identified for each animal category and dip tank. Levels of strongyle infections were classified into low, moderate and heavy based on epg. 
TABLE 1 Study sites, cattle census and total samples collected in the highveld and lowveld communal grazing areas of Zimbabwe for the period January 1999 to December 2000

\begin{tabular}{|c|c|c|c|c|c|}
\hline Region & District & $\begin{array}{l}\text { Distance from } \\
\text { nearest } \\
\text { meteorological } \\
\text { station } \\
\text { (km) }\end{array}$ & $\begin{array}{l}\text { Number of dip } \\
\text { tanks surveyed }\end{array}$ & Cattle census & $\begin{array}{l}\text { Total faecal } \\
\text { samples } \\
\text { collected }\end{array}$ \\
\hline Lowveld & $\begin{array}{l}\text { Zvishavane } \\
\text { Mberengwa } \\
\text { Plumtree }\end{array}$ & $\begin{array}{r}12 \\
14 \\
9\end{array}$ & $\begin{array}{l}3 \\
3 \\
3\end{array}$ & $\begin{array}{l}20175 \\
30649 \\
24041\end{array}$ & $\begin{array}{l}2116 \\
3174 \\
2504\end{array}$ \\
\hline Highveld & $\begin{array}{l}\text { Wedza } \\
\text { Murewa } \\
\text { Zvimba } \\
\text { Mazowe }\end{array}$ & $\begin{array}{r}8 \\
10 \\
13 \\
10\end{array}$ & $\begin{array}{l}3 \\
3 \\
3 \\
3\end{array}$ & $\begin{array}{l}30189 \\
25801 \\
12339 \\
26165\end{array}$ & $\begin{array}{l}3121 \\
1390 \\
1242 \\
2716\end{array}$ \\
\hline
\end{tabular}

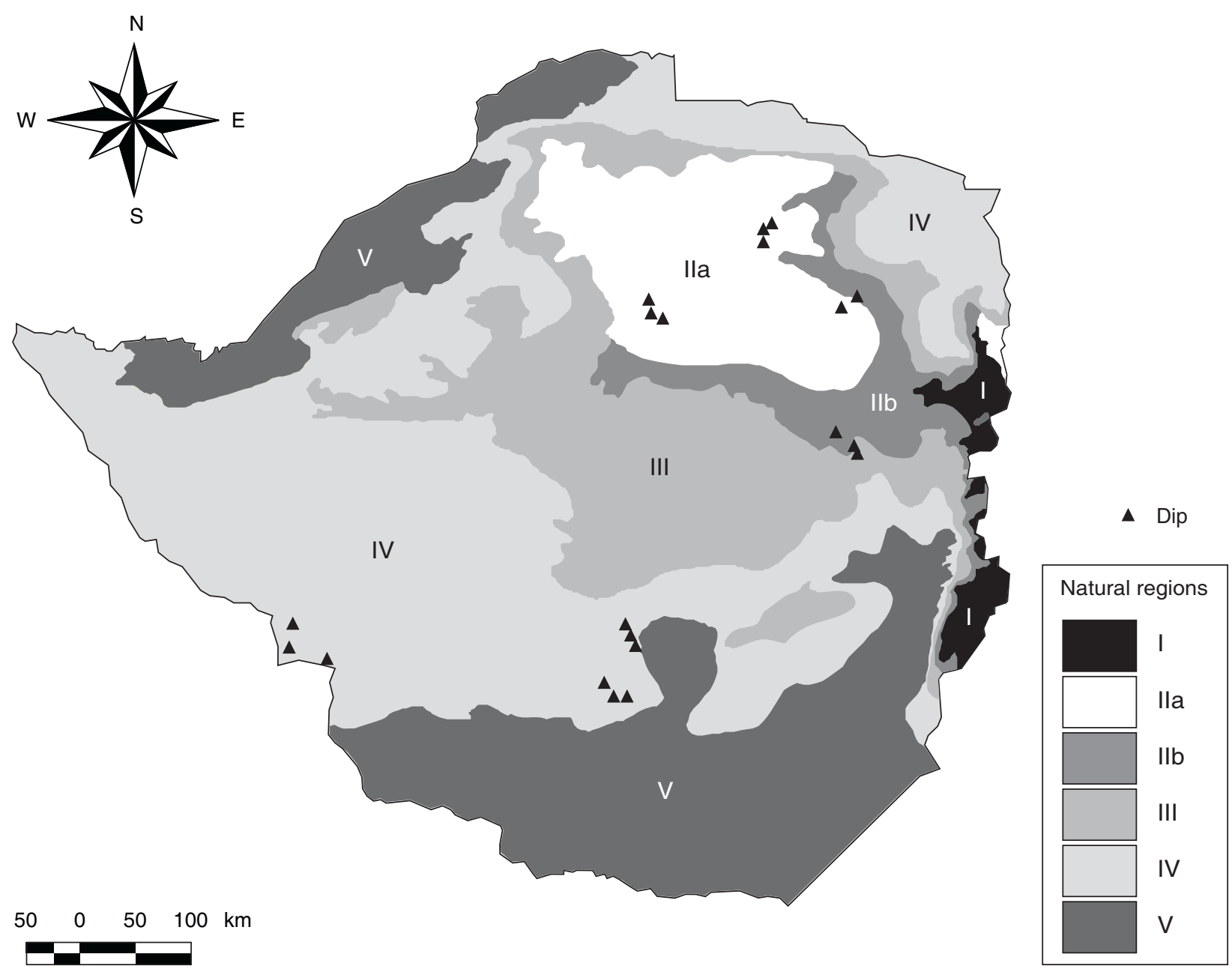

FIG. 1 Location of dips sampled in the different natural regions in the highveld and lowveld communal grazing areas of Zimbabwe

\section{Meteorological data}

Mean monthly temperatures and mean monthly rainfall data from the meteorological station nearest to each site were obtained from the recordings by the Department of Meteorology, Belvedere, Harare.

\section{Statistical analysis}

Faecal egg counts were logarithm-transformed $\left[\log _{10}\right.$ (egg count +1$\left.)\right]$ to stabilize the variance before analysis. The effect of age, sex, year, season and location on transformed egg counts was meas- 
ured by the General Linear Model (GLM) in SPSS (version 8.0). Categories were generated as follows:

- Three for age (calves $<12$ months old, weaners 1-2 years old and adults $>2$ years old)

- Nine for sex (female calves, male calves, female weaners, male weaners, dry, lactating and pregnant cows, oxen and bulls)

- Two for season (wet, November to April and dry, May to October)

- Two for locations (highveld and lowveld).

Least Square Difference (LSD) was used as the post-hoc test to measure variances between different categories. Values of $P<0.05$ were considered as significant. The correlation between egg counts and climatic factors (rainfall and temperature) was determined by a linear regression model.

\section{RESULTS}

The mean monthly temperature and rainfall during the period of study are presented in Fig. 2. Mean monthly rainfall was higher for the highveld region than the lowveld while mean monthly temperature was higher for the lowveld than the highveld. Except for these regional differences, weather values for each region were within the normal ranges.

\section{Gastrointestinal nematodes}

A total of 16264 (calves 5418, weaners 5461 and adults 5385) faecal samples was collected during the entire period of the study and $6999(43 \%)$ of the samples were positive for strongyle eggs. For both agro-ecological regions the number of animals positive for strongyle eggs differed significantly between the 2 years, with the second year having a significantly higher prevalence $(P<0.01)$ than the first year (Table 2). For both years the highveld had a significantly higher prevalence $(P<0.01)$ than the lowveld (Table 2).

For both regions, there were significant differences in prevalence of strongyle infections among the age categories $(P<0.001)$ of the cattle, with calves having a higher prevalence than the weaners and adults-except for lactating cows on highveld in both years and on lowveld in Year 2 (Table 2). Lactating \& pregnant cows had significantly higher prevalences $(P<0.01)$ than bulls, oxen and dry cows (Table 2).
FIG. 2 Mean monthly rainfall and temperature in the highveld and lowveldofZimbabwe for the period January 1999 to December 2000
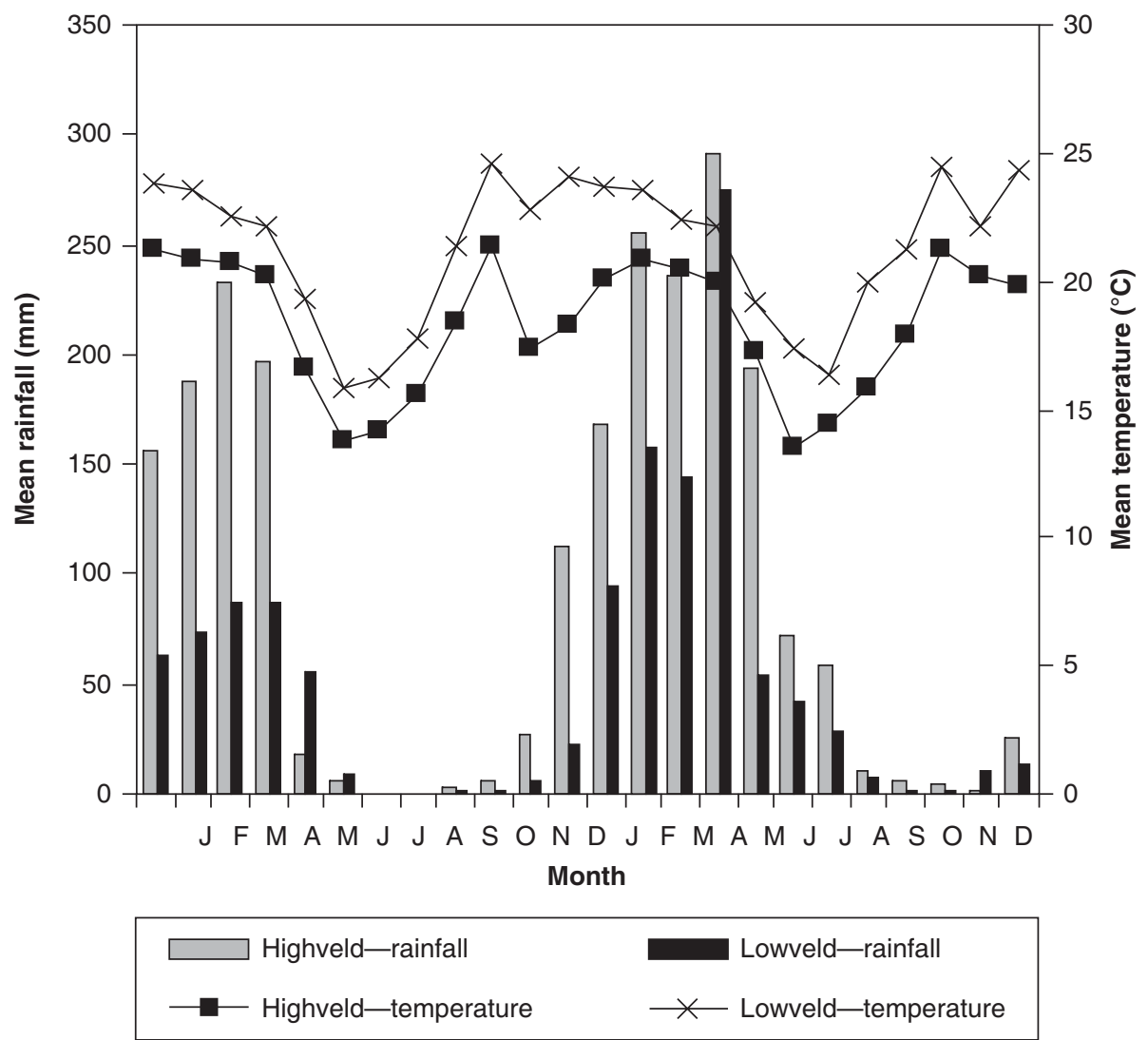


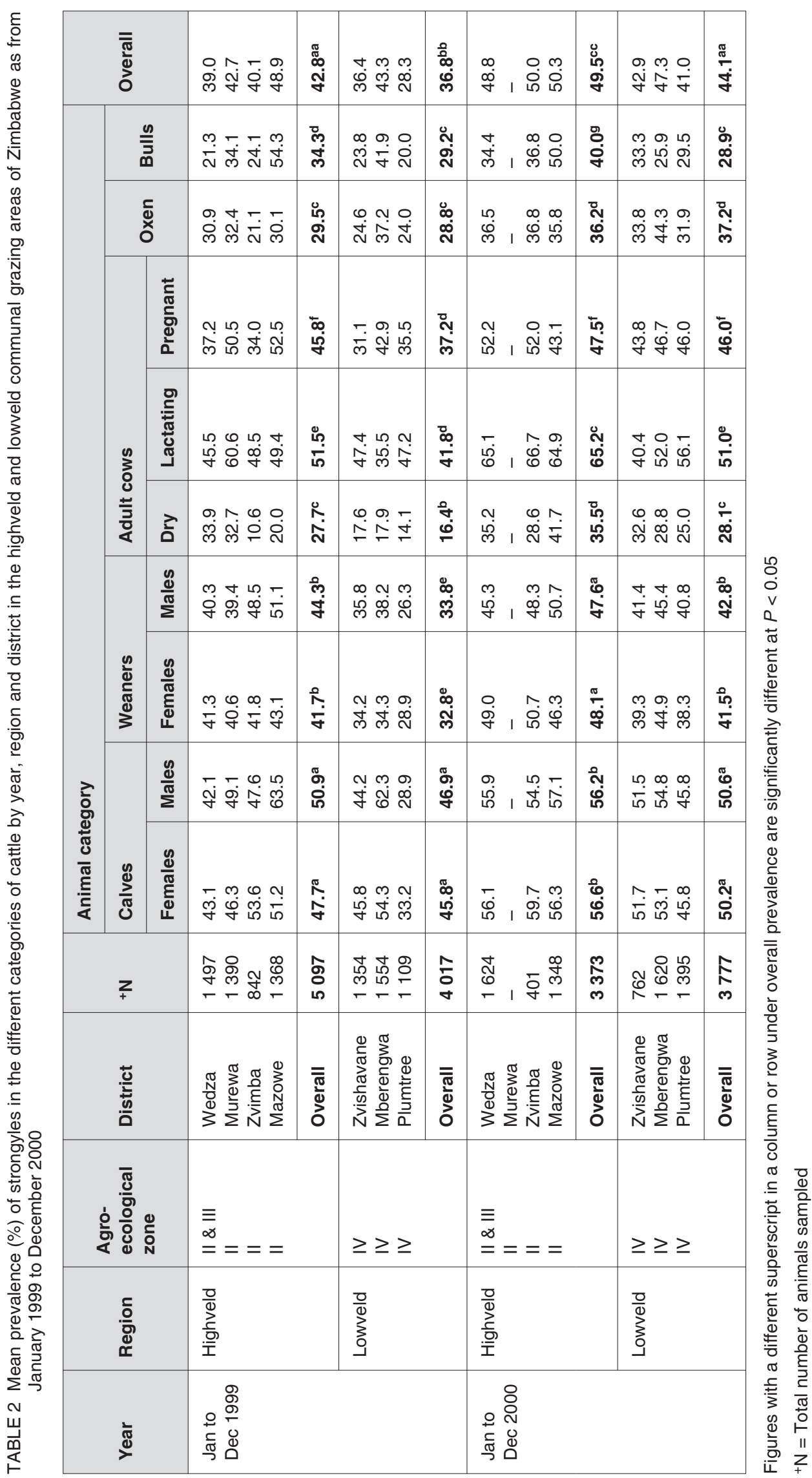


Overall, respectively $59 \%, 35 \%$ and $6 \%$ of the faecal samples had low $(<200)$, moderate $(200-700)$ and heavy $(>700)$ numbers of strongyle epg of faeces (Table 3 ). Over $6 \%$ of female and male calves, and lactating and pregnant cows recorded heavy output of eggs compared to other categories of cattle.

There were significant differences in the prevalence at different seasons of the year $(P<0.01)$ with the wet season having a significantly higher prevalence than the dry season (Table 4). Faecal egg output occurred during all the months of the 2-year period study. The mean faecal egg output rose from November/December to April/May (Fig. 3). Mean faecal egg counts were significantly higher during the wet months $(P<0.01)$ than the dry months (Fig. 3). The mean monthly faecal count was significantly higher for the highveld $(P<0.01)$ than the lowveld (Fig. 3$)$. For both regions, the mean monthly faecal egg count of calves during the wet months was significantly higher $(P<0.01)$ than that of weaners and adults (Fig. 3). Lactating and pregnant cows had a higher mean monthly faecal egg count than dry cows, bulls and oxen (Fig. 4).

The highest monthly egg count recorded during the period of study was $10600 \mathrm{epg}$ of faeces in a calf during the month of March 1999. The overall mean

TABLE 3 Levels of strongyle infections in various categories of cattle in the communal grazing areas of the highveld and lowveld for the period January 1999 to December 2000

\begin{tabular}{|l|l|l|l|}
\hline Animal category & $\begin{array}{l}\text { Low }(\mathbf{e p g}<\mathbf{2 0 0}) \\
\text { Infected cattle (\%) }\end{array}$ & $\begin{array}{l}\text { Moderate }(\mathbf{e p g} \text { 200-700) } \\
\text { Infected cattle (\%) }\end{array}$ & $\begin{array}{l}\text { Heavy (epg > 700) } \\
\text { Infected cattle (\%) }\end{array}$ \\
\hline Female calves & 56.3 & 36.1 & 7.6 \\
Male calves & 53.3 & 38.7 & 8.0 \\
Female weaners & 62.3 & 33.0 & 4.7 \\
Male weaners & 61.5 & 34.3 & 4.2 \\
Dry cows & 67.1 & 30.9 & 2.0 \\
Lactating cows & 58.8 & 33.4 & 7.8 \\
Pregnant cows & 50.9 & 40.7 & 6.8 \\
Oxen & 65.5 & 31.1 & 3.4 \\
Bulls & 70.9 & 25.8 & 3.3 \\
\hline
\end{tabular}

TABLE 4 Seasonal mean prevalence (\%) of strongyles in the different age categories of cattle by region and year in the highveld and lowveld communal grazing areas of Zimbabwe as from January 1999 to December 2000

\begin{tabular}{|c|c|c|c|c|c|c|}
\hline \multirow{2}{*}{ Season } & \multirow{2}{*}{ Region } & \multirow{2}{*}{ Age group } & \multicolumn{2}{|c|}{ Year 1 (Jan to Dec 1999) } & \multicolumn{2}{|c|}{ Year 2 (Jan to Dec 2000) } \\
\hline & & & ${ }^{\star} \mathrm{N}$ & Mean prevalence (\%) & $+\mathbf{N}$ & Mean prevalence (\%) \\
\hline \multirow[t]{4}{*}{ Wet } & \multirow[t]{2}{*}{ Highveld } & $\begin{array}{l}\text { Calves } \\
\text { Weaners } \\
\text { Adults }\end{array}$ & $\begin{array}{l}754 \\
775 \\
759\end{array}$ & $\begin{array}{l}61.5 \\
56.5 \\
47.8\end{array}$ & $\begin{array}{l}581 \\
597 \\
571\end{array}$ & $\begin{array}{l}68.0 \\
59.3 \\
55.3\end{array}$ \\
\hline & & Overall & 2288 & $55.3^{\mathrm{a}}$ & 1749 & $60.9^{b}$ \\
\hline & \multirow[t]{2}{*}{ Lowveld } & $\begin{array}{l}\text { Calves } \\
\text { Weaners } \\
\text { Adults }\end{array}$ & $\begin{array}{l}656 \\
669 \\
657\end{array}$ & $\begin{array}{l}55.6 \\
41.1 \\
39.3\end{array}$ & $\begin{array}{l}604 \\
594 \\
599\end{array}$ & $\begin{array}{l}62.7 \\
51.5 \\
46.7\end{array}$ \\
\hline & & Overall & 1982 & $45.3^{b}$ & 1797 & $53.7^{c}$ \\
\hline \multirow[t]{4}{*}{ Dry } & \multirow[t]{2}{*}{ Highveld } & $\begin{array}{l}\text { Calves } \\
\text { Weaners } \\
\text { Adults }\end{array}$ & $\begin{array}{l}955 \\
921 \\
933\end{array}$ & $\begin{array}{l}39.7 \\
31.5 \\
26.8\end{array}$ & $\begin{array}{l}536 \\
550 \\
538\end{array}$ & $\begin{array}{l}43.8 \\
35.3 \\
32.7\end{array}$ \\
\hline & & Overall & 2809 & $32.7^{c}$ & 1624 & $37.3^{d}$ \\
\hline & \multirow[t]{2}{*}{ Lowveld } & $\begin{array}{l}\text { Calves } \\
\text { Weaners } \\
\text { Adults }\end{array}$ & $\begin{array}{l}671 \\
695 \\
669\end{array}$ & $\begin{array}{l}37.2 \\
25.8 \\
22.9\end{array}$ & $\begin{array}{l}661 \\
659 \\
660\end{array}$ & $\begin{array}{l}39.2 \\
33.5 \\
33.3\end{array}$ \\
\hline & & Overall & 2035 & $28.6^{c}$ & 1980 & $35.4^{\mathrm{d}}$ \\
\hline
\end{tabular}

Figures with a different superscript within a column or row under overall prevalence are significantly different at $P<0.05$ $+\mathrm{N}=$ Total number of animals sampled 
faecal egg count for positive animals combined was 269.4 and 221.5 for the highveld and lowveld, respectively, with the highveld having a significantly higher mean faecal egg count $(P<0.01)$ than the lowveld. Calves, weaners and adults had respective overall mean faecal egg count of 280.8, 226.4 and 227.5 with that of calves being significantly higher $(P<0.01)$ than that of weaners and adults. There was a positive correlation between the faecal egg counts and rainfall $(r=0.72)$.

A

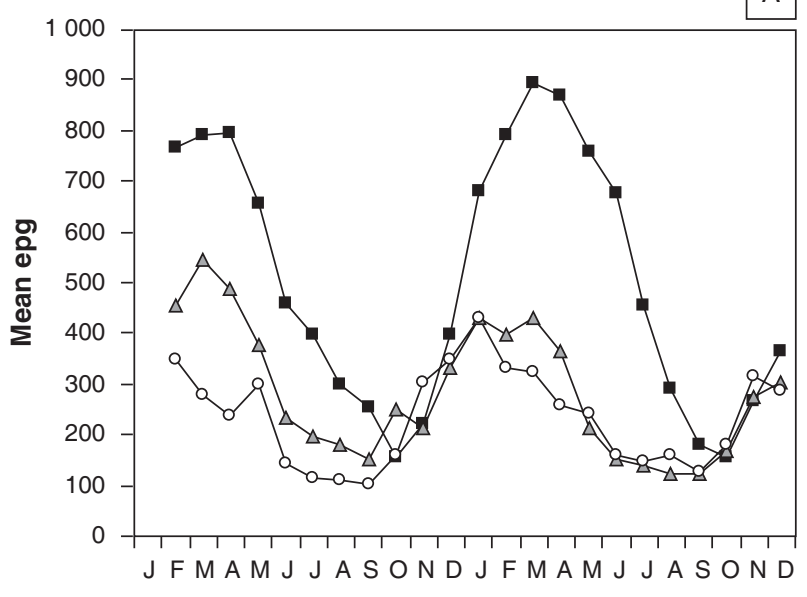

Month
Data from larval cultures indicated that the animals carried mixed parasite burdens. Cooperia $(36.2 \%)$, Haemonchus (28.4\%) and Trichostrongylus (23.7\%) were the most prevalent genera recorded. Oesophagostomum $(9.6 \%)$, Strongyloides papillosus $(2.0 \%)$ and Bunostomum (0.3\%) were less common. Only four calves and 39 adult animals were found positive for Toxocara vitulorum and Trichuris, respectively.

Table 5 shows the frequency of infective larvae $\left(L_{3}\right)$ for the different genera of nematodes found on fae-

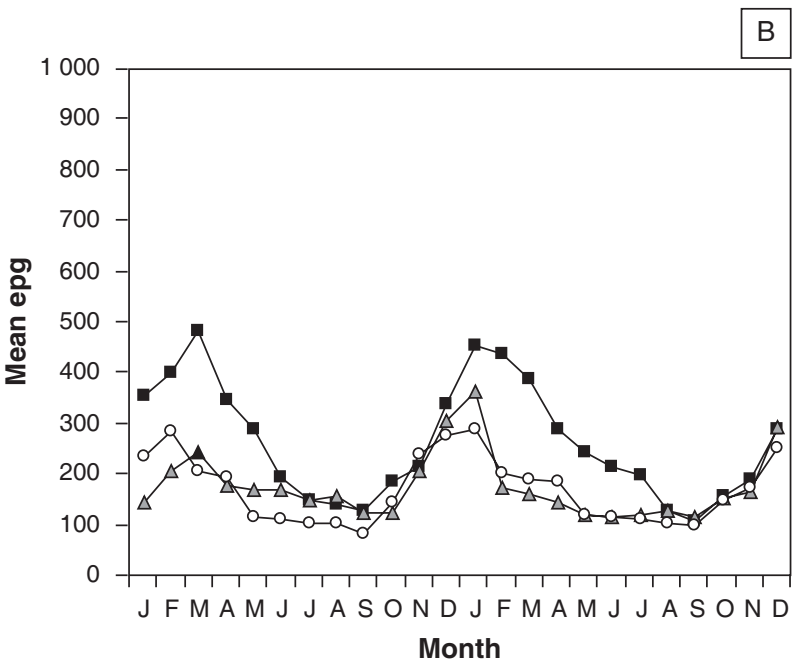

$\rightarrow$ Calves $\quad-$ Weaners $\quad \multimap$ Adults

FIG. 3 Mean monthly strongyle faecal egg counts according to age in the (a) highveld and (b) lowveld for the period January 1999 to December 2000

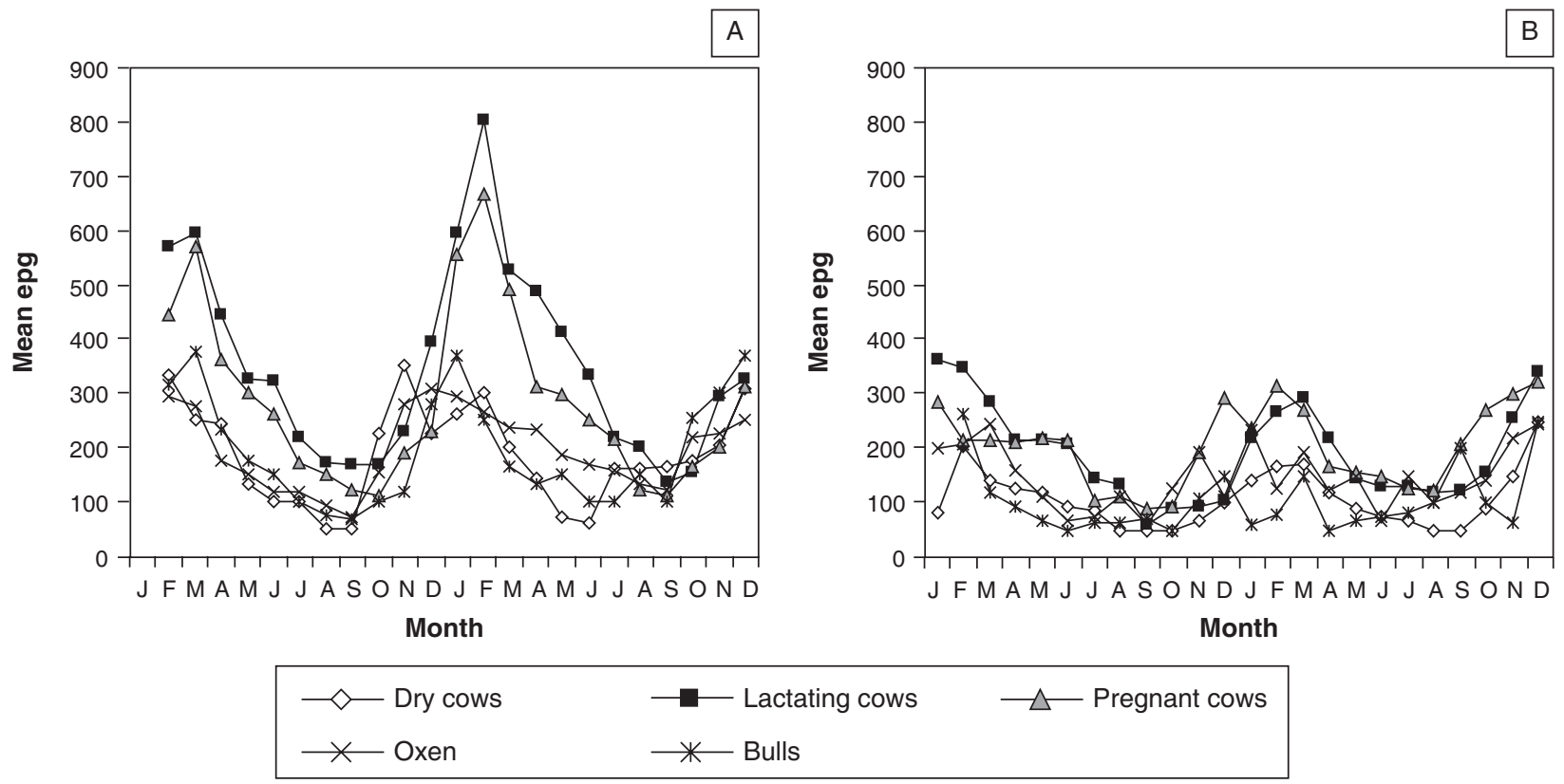

FIG. 4 Mean monthly strongyle faecal egg counts in adult cattle in the (a) highveld and (b) lowveld for the period January 1999 to December 2000 
cal culture of pooled samples in calves, weaners and adults. Strongyloides were found in calves only. No clear age trend was detected in the frequency distribution of infective larvae of the other genera of nematodes. No significant difference in the frequency occurrence of Cooperia and Oesophagostomum was observed between the highveld and lowveld. Haemonchus, Strongyloides and Bunostomum had a significantly higher occurrence in the highveld $(P$ $<0.01$ ) than in the lowveld while Trichostrongylus had a significantly higher occurrence $(P<0.01)$ in the lowveld than the highveld.
The seasonal frequencies of different genera of GI nematodes found on faecal culture of pooled samples are shown in Fig. 5. For both regions, Haemonchus occurred significantly more during the wet months of the year $(P<0.01)$ than during the dry season. There was no significant difference in the occurrence of Cooperia between the wet and dry seasons except in the second year when the dry season had a significantly $(P<0.01)$ higher prevalence than the wet season. For both regions and years, Trichostrongylus was present in significantly higher numbers during the dry months $(P<0.01)$

TABLE 5 Percent frequency of infective larvae $\left(L_{3}\right)$ of different genera of nematodes found in faecal cultures of pooled samples of three categories of cattle in the highveld and lowveld of Zimbabwe (mean \pm standard deviation) for the period January 1999 to December 2000

\begin{tabular}{|c|c|c|c|c|c|}
\hline \multirow{2}{*}{ Region } & \multirow{2}{*}{ Genus } & \multicolumn{3}{|l|}{ Age group } & \multirow{2}{*}{ Overall } \\
\hline & & Calves & Weaners & Adults & \\
\hline Highveld & $\begin{array}{l}\text { Cooperia } \\
\text { Haemonchus } \\
\text { Trichostrongylus } \\
\text { Oesophagostomum } \\
\text { Strongyloides } \\
\text { Bunostomum }\end{array}$ & $\begin{aligned} 32.0 & \pm 14.3 \\
27.9 & \pm 13.2 \\
23.3 & \pm 11.5 \\
8.0 & \pm 10.0 \\
8.4 & \pm 3.1 \\
0.4 & \pm 1.0\end{aligned}$ & $\begin{array}{l}37.6 \pm 13.2 \\
31.2 \pm 14.5 \\
21.4 \pm 12.7 \\
9.4 \pm 9.1 \\
0 \\
0.4 \pm 1.0\end{array}$ & $\begin{array}{l}38.0 \pm 14.3 \\
29.6 \pm 16.6 \\
21.9 \pm 12.6 \\
10.2 \pm 11.7 \\
0 \\
0.3 \pm 0.9\end{array}$ & $\begin{array}{c}35.9^{\mathrm{a}} \pm 13.2 \\
29.6^{\mathrm{a}} \pm 14.8 \\
23.2^{\mathrm{a}} \pm 12.3 \\
9.2^{\mathrm{a}} \pm 10.3 \\
2.8^{\mathrm{a}} \pm 3.7 \\
0.4^{\mathrm{a}} \pm 1.0\end{array}$ \\
\hline Lowveld & $\begin{array}{l}\text { Cooperia } \\
\text { Haemonchus } \\
\text { Trichostrongylus } \\
\text { Oesophagostomum } \\
\text { Strongyloides } \\
\text { Bunostomum }\end{array}$ & $\begin{array}{c}36.3 \pm 12.1 \\
27.4 \pm 12.6 \\
24.8 \pm 12.7 \\
9.1 \pm 8.2 \\
2.2 \pm 4.2 \\
0.2 \pm 1.4\end{array}$ & $\begin{array}{l}35.8 \pm 13.3 \\
25.7 \pm 13.4 \\
26.3 \pm 12.2 \\
10.5 \pm 10.3 \\
0 \\
0.2 \pm 1.7\end{array}$ & $\begin{array}{l}37.5 \pm 13.9 \\
28.2 \pm 13.2 \\
24.2 \pm 11.1 \\
10.0 \pm 9.0 \\
0 \\
0.1 \pm 2.5\end{array}$ & $\begin{array}{c}36.5^{\mathrm{a}} \pm 13.1 \\
27.1^{\mathrm{b}} \pm 13.1 \\
25.1^{\mathrm{b}} \pm 12.0 \\
9.9^{\mathrm{a}} \pm 9.2 \\
1.2^{\mathrm{b}} \pm 1.6 \\
0.2^{\mathrm{b}} \pm 1.4\end{array}$ \\
\hline
\end{tabular}

Figures with a different superscript for the same species in a column are significantly different at $P<0.05$
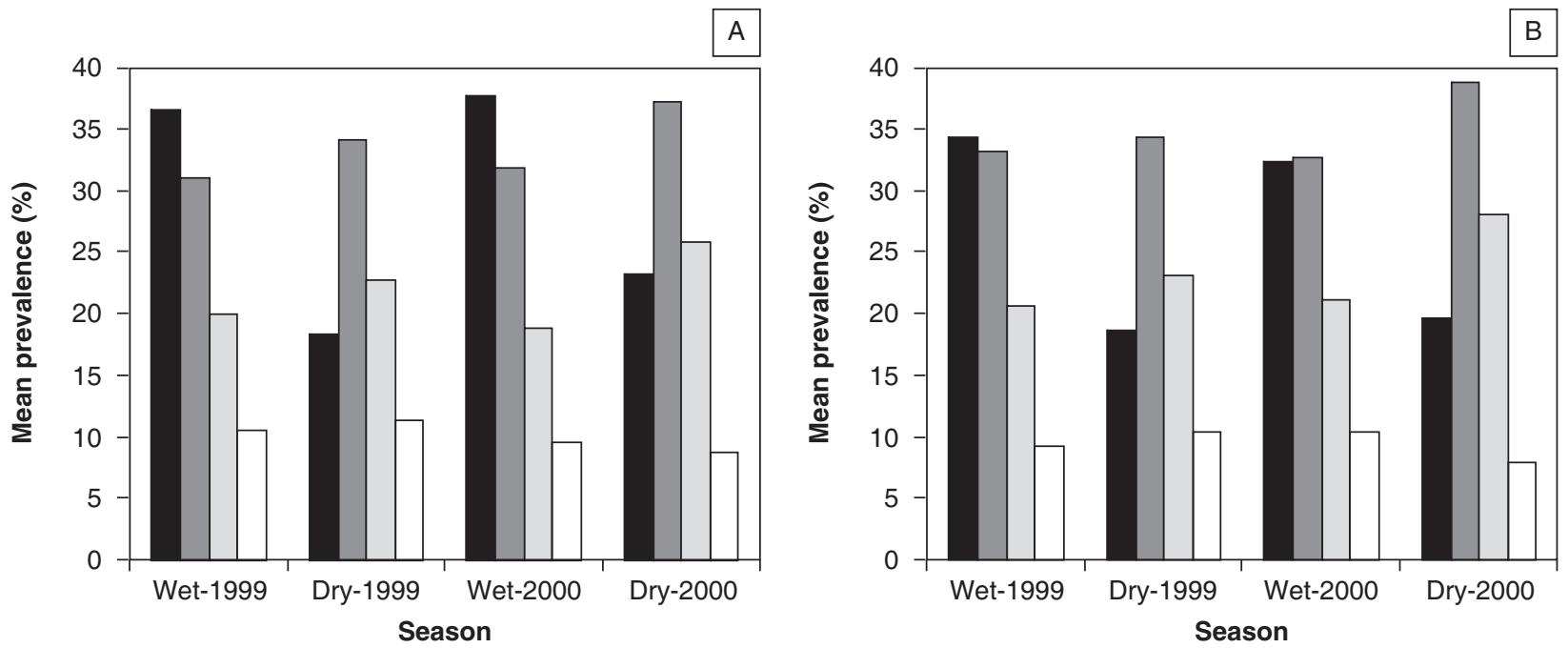

$\square$ Haemonchus $\square$ Cooperia $\square$ Trichostrongylus $\square$ Oesophagostomum

FIG. 5 Seasonal frequency (\%) of infective larvae (L3) of strongyles in faecal cultures of pooled samples of communal grazing cattle in the (a) highveld and (b) lowveld of Zimbabwe for the period January 1999 to December 2000 


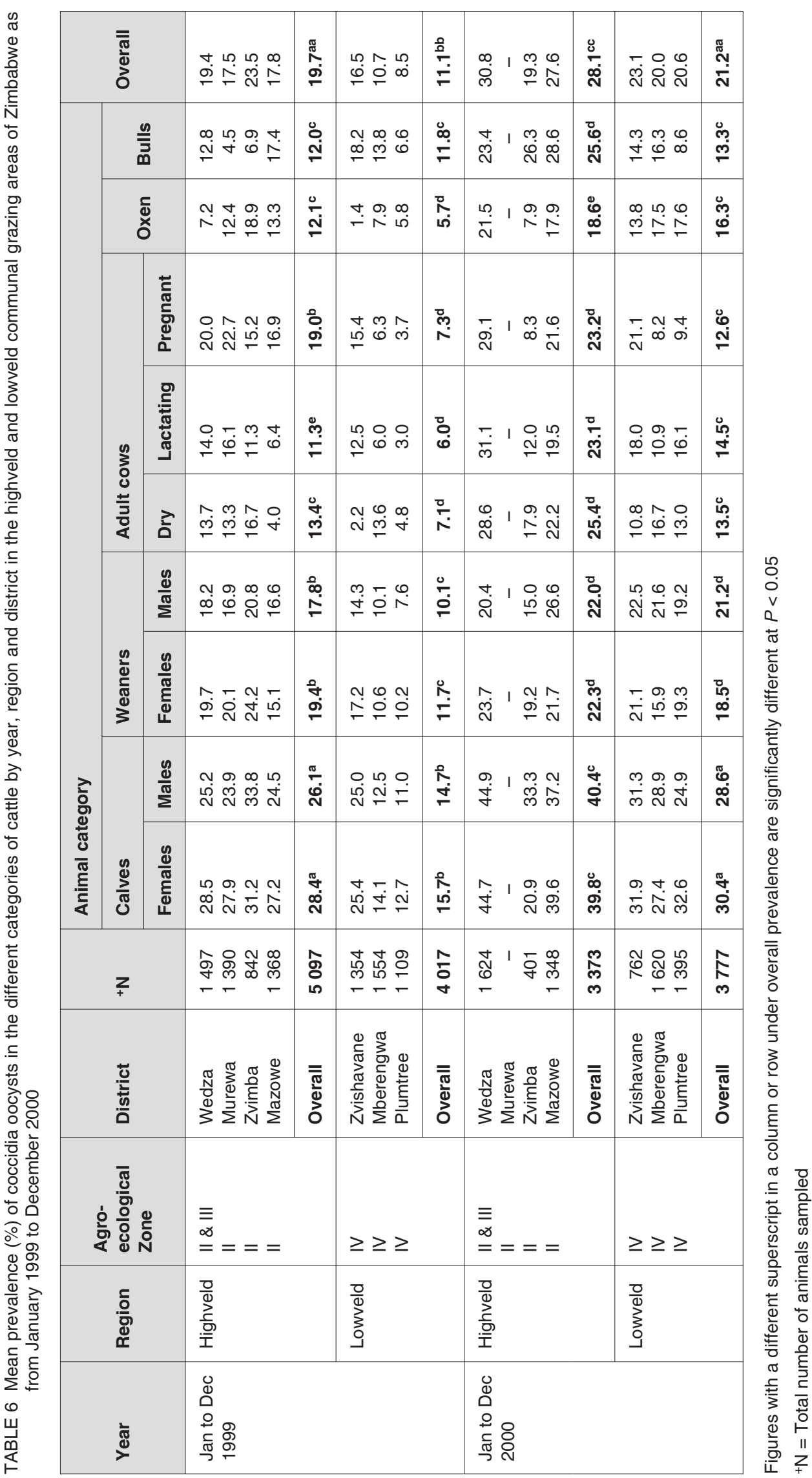


Parasitic gastrointestinal nematodes, cestodes and coccidia infections in cattle in Zimbabwe

TABLE 7 Seasonal mean prevalence (\%) of coccidia oocysts in the different age categories of cattle by region and year in the highveld and lowveld communal grazing areas of Zimbabwe as from January 1999 to December 2000

\begin{tabular}{|c|c|c|c|c|c|c|}
\hline \multirow{2}{*}{ Season } & \multirow{2}{*}{ Region } & \multirow{2}{*}{ Age group } & \multicolumn{2}{|c|}{ Year 1 (Jan to Dec 1999) } & \multicolumn{2}{|c|}{ Year 2 (Jan to Dec 2000) } \\
\hline & & & ${ }^{*} \mathrm{~N}$ & Mean prevalence (\%) & $+\mathrm{N}$ & Mean prevalence (\%) \\
\hline \multirow{4}{*}{ Wet } & \multirow[t]{2}{*}{ Highveld } & $\begin{array}{l}\text { Calves } \\
\text { Weaners } \\
\text { Adults }\end{array}$ & $\begin{array}{l}754 \\
775 \\
759\end{array}$ & $\begin{array}{l}33.0 \\
23.1 \\
15.4\end{array}$ & $\begin{array}{l}581 \\
597 \\
571\end{array}$ & $\begin{array}{l}41.5 \\
29.6 \\
26.6\end{array}$ \\
\hline & & Overall & 2288 & $23.8^{a}$ & 1749 & $32.6^{\mathrm{b}}$ \\
\hline & \multirow[t]{2}{*}{ Lowveld } & $\begin{array}{l}\text { Calves } \\
\text { Weaners } \\
\text { Adults }\end{array}$ & $\begin{array}{l}656 \\
669 \\
657\end{array}$ & $\begin{array}{r}18.2 \\
13.3 \\
8.8\end{array}$ & $\begin{array}{l}604 \\
594 \\
599\end{array}$ & $\begin{array}{l}36.0 \\
22.7 \\
16.9\end{array}$ \\
\hline & & Overall & 1982 & $13.5^{c}$ & 1797 & $25.2^{\mathrm{d}}$ \\
\hline \multirow{4}{*}{ Dry } & \multirow[t]{2}{*}{ Highveld } & $\begin{array}{l}\text { Calves } \\
\text { Weaners } \\
\text { Adults }\end{array}$ & $\begin{array}{l}955 \\
921 \\
933\end{array}$ & $\begin{array}{l}22.7 \\
14.9 \\
11.3\end{array}$ & $\begin{array}{l}536 \\
550 \\
538\end{array}$ & $\begin{array}{l}38.6 \\
14.0 \\
17.7\end{array}$ \\
\hline & & Overall & 2809 & $16.3^{b}$ & 1624 & $23.4^{d}$ \\
\hline & \multirow[t]{2}{*}{ Lowveld } & $\begin{array}{l}\text { Calves } \\
\text { Weaners } \\
\text { Adults }\end{array}$ & $\begin{array}{l}671 \\
695 \\
669\end{array}$ & $\begin{array}{r}12.4 \\
8.8 \\
5.5\end{array}$ & $\begin{array}{l}661 \\
659 \\
660\end{array}$ & $\begin{array}{l}23.2 \\
17.0 \\
12.0\end{array}$ \\
\hline & & Overall & 2035 & $8.9^{d}$ & 1980 & $17.4^{\mathrm{a}}$ \\
\hline
\end{tabular}

Figures with a different superscript within a column or row under overall prevalence are significantly different at $P<0.05$

${ }^{+} \mathrm{N}=$ Total number of animals sampled

than the wet months while there was no significant difference in the occurrence of Oesophagostomum between the wet and dry seasons.

\section{Coccidia}

Overall, oocysts were recorded in $19.8 \%$ of the samples with the highveld having a significantly higher prevalence $(P<0.01)$ than the lowveld. The prevalence differed significantly between the 2 years with the second year having a significantly higher prevalence $(P<0.01)$ than the first year (Table 6$)$.

For both regions, there were significant differences in prevalence among the age categories $(P<0.001)$, with calves having a higher prevalence than the adults (Table 6). Calves had significantly $(P<0.001)$ higher opg of faeces than the adults.

The highest oocyst count recorded during the period of study was 29400 opg of faeces in a calf in February 1999 . Of the total animals infected, $5.6 \%$ were shedding more than $1000 \mathrm{opg}$, with $8.1 \%, 2.6 \%$ and $4.5 \%$ of infected calves, weaners and adults shedding more than 1000 opg, respectively. During the wet season the prevalence was significantly higher $(P<0.01)$ than during the dry season (Table 7). Mean faecal oocyst counts were similarly signifi- cantly higher during the wet months than the dry months.

\section{Cestodes}

The only recorded cestode spp. was Moniezia benedeni and $4.8 \%$ of the samples were positive for it. There was no significant difference in number of animals positive for cestodes between the two regions. The wet season had a significantly higher prevalence $(P<0.01)$ than the dry season. However, in the lowveld there was no significant difference between the two seasons in the second year.

\section{DISCUSSION}

\section{Gastrointestinal nematodes}

The present study clearly demonstrated the effect of age on the occurrence of GI nematodes with the prevalence being highest in animals aged less than 12 months and lowest in adult cattle. This conforms to earlier reports (Anene, Onyekwodiri, Chime \& Anika 1994; Vassilev 1994, 1999; Waruiru, Kyvsgaard, Thamsborg, Nansen, Bogh, Munyua \& Gathuma 2000), which showed that the susceptibility and 
pathogenicity of nematode infections were greater in young animals than in mature animals.

During lactation, and sometimes during late pregnancy, the immune response of the host to gastrointestinal nematodes is partially suppressed leading to an increase in the population of worms and at the same time the fecundity of female worms in previously immune hosts may also increase to approach that of worms in fully susceptible animals (Connan 1976). The present data and earlier reports (Borgsteede 1978; Hammerberg \& Lamm 1980) revealed higher prevalence and egg counts of nematodes in lactating and pregnant cows compared to dry cows, bulls and oxen. Hence, lactating and pregnant cows might serve as a source of pasture contamination.

When cattle graze on natural pasture, climate plays an important role in the transmission of worms (Gatongi, Gathuma \& Munyua 1987). From this study and earlier studies (Anene et al. 1994; Moyo et al. 1996; Lima 1998; Dreyer, Fourie \& Kok 1999; Jithendran \& Bhat 1999) the effect of climate on the prevalence of GI nematodes was evident. The overall prevalence and egg counts of nematodes were related to the climatic conditions (rainfall and temperature) (Fig. 2). During the wet months (December to March), rainfall and temperature were probably more favourable for the development and survival of the pre-parasitic stages (Durie 1961), leading to increased availability of infective larvae on the pasture. This resulted in an increase in egg counts with peaks between February and April. During the dry season pasture larval counts were reported to be low in communal grazing areas of Zimbabwe (Moyo et al. 1996). Hence, the decline in egg counts and prevalence during the dry months may be attributed to the lack of rainfall, a condition unfavourable for the development of eggs to infective larvae.

The spectrum of strongyles encountered in cattle in the present study has previously been reported in Zimbabwe (Pandey et al. 1993; Vassilev 1994, 1999; Moyo et al. 1996) and elsewhere in Africa (Anene et al. 1994; Ndao, Pandey, Zinsstag \& Pfister 1995; Waruiru, Thamsborg, Nansen, Kyvsgaard, Bogh, Munyua \& Gathuma 2001). The predominance of Cooperia spp. agrees with earlier reports in Zimbabwe (Pandey et al. 1993; Moyo et al. 1996; Vassilev 1999). The pathogenic effects of Cooperia spp. are not well known, but species from this genus are reported not to be as pathogenic as other genera like Haemonchus and Trichostrongylus (Vassilev 1999) and are not generally considered to be of great importance in terms of production losses (Bianchin \& Honer 1987). Anderson, Armour, Jarrett, Jennings,
Ritchie \& Urquhart (1965) reported no evidence of pathogenicity of $C$. punctata in cattle in Northern Nigeria. However, Becklund (1962), Herlich (1962) and Henderson \& Kelly (1978), considered large numbers of Cooperia spp. to be potentially pathogenic in susceptible calves. Alicata \& Lynd (1961) found that calves given 250000 C. punctata infective larvae developed clinical signs of helminthosis, but added that individual calves varied in their reaction. Owen \& Talbot (1983) found massive burdens of $C$. punctata in dead weaners and were of the opinion that they were an important factor in at least accelerating their deaths. The high numbers of $\mathrm{CoO}-$ peria spp. found in the present study could probably affect productivity especially during the dry season when pastures are poor and scanty.

In Brazil, the highest number of Cooperia $L_{3}$ was observed during the rainy season (Lima 1998). However, transmission occurred even in the dry season despite the relatively low rainfall during that period and the data indicated that Cooperia $\mathrm{L}_{3}$ were more resistant to heat and dryness and had a better ability to migrate than other nematode species (Lima 1998). Similar observations have been reported by Reinecke (1960) and Durie (1962). Results of the present study also indicated that Cooperia $\mathrm{L}_{3}$ were probably more resistant to adverse conditions of heat and dryness as high numbers were observed during both the wet and dry seasons.

Haemonchus spp. were second in prevalence after Cooperia. The genus is reported as a cause of primary disease, particularly in young animals (Vassilev 1999). High numbers of Haemonchus spp. have been obtained from cattle during the wet season (Vassilev 1994; Ndao et al. 1995; Lima 1998). The present data indicated significantly higher prevalence of Haemonchus spp. during the wet months of the year than during the dry season. During the wet season, temperature and rainfall in the survey areas were probably more suitable for the development and survival of the free-living stages of Haemonchus spp. than during the dry season. Another reason for the low prevalence of Haemonchus spp. during the dry season may be the occurrence of hypobiosis shown to occur in the highveld area of Zimbabwe during the same period of the year (Moyo et al. 1996).

Trichostrongylus species were also prevalent and their role in parasitic gastroenteritis is reported to be only additive to Haemonchus spp. (Vassilev 1999). In Brazil, Trichostrongylus spp. were more frequently observed during the dry season when temperatures were lower than during the rainy season (Lima 
1998). It has been reported that lower temperature is required for the development of the free-living stages of this genus (Williams \& Mayhew 1967). Higher monthly percent frequency of infective larvae of Trichostrongylus spp. were observed during the cold dry months (May to August). These findings are corroborative evidence of lower temperatures as a requirement for the development of the free-living stages of this genus.

Low numbers of Oesophagostomum spp. were observed during the present study and no seasonal trends were obtained for this genus. In Colombia, small numbers of Oesophagostomum spp. were observed in calves and this was attributed to the relatively long life cycle and low resistance to desiccation of the pre-infective stages of this genus (Rivera, Parra, Garcia \& Ayeardi 1983), which account for the low prevalence noted during the present study. In Brazil, Oesophagostomum spp. were also present in low numbers in most months of the year, but large numbers were observed occasionally during the rainy season (Lima 1998).

Strongyloides spp. have been reported to be common in calves only (Moyo et al. 1996; Lima 1998; Vassilev 1999; Waruiru et al. 2000). Egg counts of Strongyloides spp. in calves were observed to diminish with increasing age of the calves with low levels reached when calves were 6 to 8 months of age (Rivera et al. 1983; Lima 1998). The present study indicated the presence of Strongyloides spp. in calves only.

Bunostomum spp. were found at low levels but they probably do not affect productivity. Infection with Bunostomum spp. under extensive range-type operations with low animal density is reported to be greatly reduced since the parasite's larvae do not migrate from faeces, but penetrate the host's skin (Rivera et al. 1983) which probably accounted for the low prevalence noted in the present study. The prevalence of Bunostomum spp. has been reported to be high during the wet season (Owen \& Talbot 1983) and similar observations were made during the present study. Lee, Armour \& Ross (1960) observed that rainfall is the most important element controlling the development of this parasite.

Toxocara vitulorum is an infrequent parasite under extensive conditions (Bianchin \& Honer 1987). During the present study only four calves and 39 animals were found positive for T. vitulorum and Trichuris, respectively. Hence, both parasites are probably of little significance in the health of cattle in the study area. However, on effluent-irrigated pastures on one farm in Harare, Zimbabwe, a high prevalence of $T$. vitulorum in calves has been reported (Pandey, Hill, Hensman \& Baragwanath 1990). An enquiry (Pandey et al. 1990) to several nearby farms on traditional pasture management revealed that none had experienced $T$. vitulorum infection. Pandey et al. (1990) concluded that it would appear that $T$. vitulorum infection is focal in nature and the high prevalence noted on the studied farm could probably due to the unique system of farm management resulting in persistent moist/wet pastures.

\section{Coccidia}

During the present study, a significantly higher proportion of calves were infected with coccidia than adult cattle. This agrees with earlier reports from Kenya (Munyua \& Ngotho 1990; Waruiru, Mbuthia \& Kimoro 1993; Waruiru et al. 2000), Nigeria (Anene et al. 1994), South Africa (Matjila \& Penzhorn 2002), India (Jithendran \& Bhat 1999) and the Netherlands (Cornelissen, Verstegen, Van den Brand, Perie, Eysker, Lam \& Pijpers 1995). In cattle, clinical coccidiosis occurs mainly in young animals (Munyua \& Ngotho 1990). During the present study, no clinical cases were observed in young or adult animals, but the results showed that calves are the major source of pasture contamination.

During the rainy season, high humidity and moderate temperature are factors that facilitate the survival and sporulation of the oocysts (Troncy 1989). Results of the present study showed seasonal variation in the prevalence of coccidia, with the prevalence and level of infection being higher during the rainy season than the dry season.

\section{Cestodes}

In Colombia, Rivera et al. (1983) observed that egg counts from Moniezia spp. increased with the calves' age peaking at 8-10 months of age and thereafter diminished considerably after 1 year of age. The present study indicated that the prevalence of $M$. benedeni was low and mainly in young animals. A significantly higher prevalence of this parasite was recorded during the rainy season which agrees with earlier reports (Negesse 1994; Vassilev 1994).

The present data revealed that the wet months (December to March) were the highest risk for occurrence of gastrointestinal parasites while young animals had the highest risk of infection. A broadspectrum anthelmintic administered during January/ February will control immature and mature forms of the GI nematodes. In July/August, a broad-spectrum 
anthelmintic should be administered and provided it is effective against arrested larvae, it will have an extended effect against Haemonchus spp., Cooperia spp. and Trichostrongylus spp. If infection with Haemonchus spp. is particularly severe during the rainy season, treatments with narrow-spectrum anthelmintics effective against this species should be administered.

Magaya, Mukaratirwa, Mutisi, Kyvsgaard \& Thamsborg (2000) examined the effects of treatment with Fenbendazole Slow-Release bolus on the productivity of indigenous cattle on communal pastures in Sanyati area, Zimbabwe. Faecal worm egg counts were found to be significantly lower in the bolus treated group than in the control group. More studies on the use of controlled slow release systems in the communal farming areas of Zimbabwe should be assessed. These systems would probably be of importance especially during the rainy season. Conder, Rooney, Illyes, Keller, Meinert \& Logan (1998) demonstrated that topical application of doramectin significantly reduced faecal egg counts by $99.9 \%$ in treated cattle compared to controls. They expressed the view that doramectin in a pour-on formulation should provide a useful new treatment for controlling nematode parasites in cattle. The use of pour-on methods need assessment in Zimbabwe and would probably be effective in communal grazing areas.

However, whatever control strategy is employed, it is imperative that it should be village-based as cattle in communal areas are grazed together and there is no benefit for only a few to carry out the recommended control measures. The anthelmintic treatment should be organized and preferably done at the same time within a village.

\section{ACKNOWLEDGEMENTS}

We thank the Danish International Development Agency (DANIDA) as part of the ENRECA Livestock Helminth Research Project who sponsored the studies. Grateful thanks are due to laboratory staff of the Parasitological Section, Department of Paraclinical Veterinary Studies and the Central Veterinary Laboratory for their able assistance with the helminthological work. The Department of Meteorology, Belvedere, Harare is thanked for kindly providing climatic data of the studied districts.

\section{REFERENCES}

ALICATA, J.E. \& LYND, F.T. 1961. Growth rate and signs of infections in calves experimentally infected with Cooperia punctata. American Journal of Veterinary Research, 22:704707.

ANDERSON, N., ARMOUR, J., JARRETT, W.F.H., JENNINGS, F.W., RITCHIE, J.D. \& URQUHART, G.M. 1965. A field study of parasitic gastritis in cattle. Veterinary Record, 77:11961204.

ANENE, B.M., ONYEKWODIRI, E.O., CHIME, A.B. \& ANIKA, S. M. 1994. A survey of gastrointestinal parasites in cattle of southeastern Nigeria. Preventive Veterinary Medicine, 20: 297-306.

BECKLUND, W.W. 1962. Helminthiases in Georgia cattle-A clinical and economic study. American Journal of Veterinary Research, 23:510-515.

BIANCHIN, I. \& HONER, M.R. 1987. Helminth parasites of beef cattle in the Cerrado Region of Brazil. Tropical Animal Health and Production, 19:39-45.

BORGSTEEDE, F.H.M. 1978. Observations on the post-parturient rise of nematode egg-output in cattle. Veterinary Parasitology, 4:385-391.

CONDER, G.A., ROONEY, K.A., ILLYES, E.F., KELLER, D.S., MEINERT, T.R \& LOGAN, N.B. 1998. Field efficacy of doramectin pour-on against naturally acquired gastrointestinal nematodes of cattle in North America. Veterinary Parasitology, 77:259-265.

CONNAN, R.M. 1976. Effect of lactation on the immune response to gastrointestinal nematodes. Veterinary Record, 99:76477.

CORNELISSEN, A.W.C.A., VERSTEGEN, R., VAN DEN BRAND, H., PERIE, N.M., EYSKER, M., LAM, T.J.G.M. \& PIJPERS, A. 1995. An observational study of Eimeria species in housed cattle on Dutch dairy farms. Veterinary Parasitology, 56:7-16.

DREYER, K., FOURIE, L.J. \& KOK, D.J. 1999. Gastro-intestinal parasites of cattle in the communal grazing system of Botshabelo in the Free State. Onderstepoort Journal of Veterinary Research, 66:145-149.

DURIE, P.H. 1961. Parasitic gastroenteritis of cattle: the distribution and survival of infective strongyle larvae on pasture. Australian Journal of Agricultural Research, 12:1200-1211.

DURIE, P.H. 1962. Parasitic gastroenteritis of cattle: seasonal fluctuation of populations of strongyle larvae on a calf pasture and their significance in infection of the grazing animal. Australian Journal of Agricultural Research, 13:776-777.

GATONGI, P.M., GATHUMA, J.M. \& MUNYUA, W.K. 1987. The prevalence of gastrointestinal nematodes in cattle in Tetu Division of Nyeri District, Kenya. Bulletin of Animal Health and Production in Africa, 35:294-297.

HAMMERBERG, B. \& LAMM, W.D. 1980. Changes in periparturient faecal egg counts in beef cows calving in the spring. American Journal of Veterinary Research, 41:1686-1689.

HENDERSON, A.W.K. \& KELLY, J.D. 1978. Helminth parasites of beef cattle in the East Kimberley and Victoria River Districts of Northern Australia. Tropical Animal Health and Production, $10: 63-73$.

HERLICH, H. 1962. Studies on calves experimentally infected with combinations of four nematode species. American Journal of Veterinary Research, 23:521-528.

JITHENDRAN, K.P. \& BHAT, T.K. 1999. Epidemiology of parasitoses in dairy animals in the North West Humid Himalaya Region of India with particular reference to gastrointestinal nematodes. Tropical Animal Health and Production, 31:205214. 
LEE, R.P., ARMOUR, J. \& ROSS, J.G. 1960. The seasonal variations of strongyle infestations in Nigerian Zebu cattle. British Veterinary Journal, 44:326-328.

LIMA, W.S. 1998. Seasonal infection pattern of gastrointestinal nematodes of beef cattle in Minas Gerais State, Brazil. Veterinary Parasitology, 74:203-214.

MAGAYA, A., MUKARATIRWA, S., MUTISI, C., KYVSGAARD, N. \& THAMSBORG, S. 2000. Effects of Fenbendazole slowrelease (SR) bolus on productivity of indigenous cattle on communal pasture in Sanyati area, Zimbabwe. Zimbabwe Veterinary Journal, 31:29-40.

MATJILA, P.T. \& PENZHORN, B.L. 2002. Occurrence and diversity of bovine coccidia at three localities in South Africa. Veterinary Parasitology, 104:93-202.

MINISTRY OF AGRICULTURE, FISHERIES \& FOOD 1986. Manual of Veterinary Parasitological Laboratory Techniques. Reference Book 418. London: Her Majesty's Office.

MOYO, D.Z., BWANGAMOI, O., HENDRIKX, W.M.L. \& EYSKER, M. 1996. The epidemiology of gastrointestinal nematode infections in communal cattle and commercial beef cattle on the highveld of Zimbabwe. Veterinary Parasitology, 67:105120.

MUNYUA, W.K. \& NGOTHO, J.W. 1990. Prevalence of Eimeria species in cattle in Kenya. Veterinary Parasitology, 15:163168.

NDAO, M., PANDEY, V.S., ZINSSTAG, J. \& PFISTER, K. 1995. Helminth parasites and hypobiosis of nematodes in N'Dama cattle during the dry season in The Gambia. Veterinary Parasitology, 60:161-166.

NEGESSE, T. 1994. Prevalence of bovine flatworms in different classes of cattle at different seasons and altitudes of southern Ethiopia. Bulletin of Animal Health and Production in Africa, 42:199-203.

OBWOLO, M.J., HILL, F.W.G., NYATHI, C.B., OGAA, J.S., ODIAWO, G.O., LLEWELYN, C.A. VICKERS, D.B. \& MOYO, P. 1992. Studies on indigenous cattle under traditional management in Zimbabwe. 1, Endoparasites. Zimbabwe Veterinary Journal, 23:101-106.

OWEN, I.L. \& TALBOT, N.T. 1983. Importance of gastrointestinal helminths in calves in Papua New Guinea. Tropical Animal Health and Production, 15:115-123.

PANDEY, V.S. 1989. Helminth Infections in Ruminants in Zimbabwe, in Livestock production and diseases in the tropics, edited by J. Kuli, R.S. Paling \& J.E. Huhn. Faculty of Veterinary Medicine, Utrecht, The Netherlands.
PANDEY, V.S., HILL, F.W.G., HENSMAN, D.G. \& BARAGWANATH, L.C. 1990. Toxocara vitulorum in beef calves kept on effluent-irrigated pastures in Zimbabwe. Veterinary Parasitology, 35:349-355.

PANDEY, V.S., CHITATE, F. \& NYANZUNDA, T.M. 1993. Epidemiological observations on gastro-intestinal nematodes in communal land cattle from the highveld of Zimbabwe. Veterinary Parasitology, 51:99-106.

REINECKE, R.K. 1960. A field study of some nematode parasites of bovines in a semi-arid area, with special reference to their biology and possible methods of prophylaxis. Onderstepoort Journal of Veterinary Research, 28:365-404.

RIVERA, B., PARRA, D., GARCIA, O. \& AYCARDI, E. 1983. Gastrointestinal parasites in calves in Colombia. Tropical Animal Health and Production, 15:107-114.

TRONCY, P.M. 1989. Helminths of livestock and poultry in tropical Africa, in Manual of Tropical Veterinary Parasitology, translated by Shah-Fischer \& R. Ralph Say. Wallingford, UK: $\mathrm{CAB}$ International.

VASSILEV, G.D. 1994. Prevalence and seasonality of internal parasite infections detectable by faecal examination of cattle in Chiweshe communal farming area of Zimbabwe. Zimbabwe Veterinary Journal, 25:41-51.

VASSILEV, G.D. 1999. Prevalence of internal parasite infections of cattle in the communal farming areas of Mashonaland East Province, Zimbabwe. Zimbabwe Veterinary Journal, 30: $1-17$.

WARUIRU, R.M., MBUTHIA, P.G. \& KIMORO, C.O. 1993. Prevalence of gastrointestinal parasites and liver flukes in calves in Mathira Division of Nyeri District, Kenya. Bulletin of Animal Health and Production in Africa, 41:291-296.

WARUIRU, R.M., KYVSGAARD, N.C., THAMSBORG, S.M., NANSEN, P., BØGH, H.O., MUNYUA, W.K. \& GATHUMA, J.M. 2000. Prevalence and intensity of helminth and coccidial infections in dairy cattle in Central Kenya. Veterinary Research Communications, 24:39-53.

WARUIRU, R.M., THAMSBORG, S.M., NANSEN, P., KYVSGAARD, N.C., BØGH, H.O., MUNYUA, W.K. \& GATHUMA, J.M. 2001. The epidemiology of gastrointestinal nematodes of dairy cattle in Central Kenya. Tropical Animal Health and Production, 33:173-187.

WILLIAMS, J.C. \& MAYHEW, R.L. 1967. Survival of infective larvae of the cattle nematodes Cooperia punctata, Trichostrongylus axei and Oesophagostomum radiatum. American Journal of Veterinary Research, 28:629. 